\author{
Ji-Feng Ding \\ Jung-Fong Kuo \\ Wen-Hui Tai
}

http://dx.doi.org/10.21278/brod70107

\title{
A FUZZY EVALUATION MODEL OF CHOOSING A MIDDLE MANAGER FOR AN INTERNATIONAL SHIPPING SERVICE PROVIDER
}

UDC 323.3-057.17

Professional paper

\begin{abstract}
Summary
Choosing a middle manager with management competency and capabilities will have a decisive influence on the organization's development for international shipping service providers. There is ambiguity and uncertainty in the decision-making environment during the selection of a middle manager and many evaluation criteria must be considered. The main purpose of this article is to construct a fuzzy multiple criteria decision-making (MCDM) model for international shipping service providers to use when selecting a middle manager. First, some methods and concepts of the fuzzy theory are introduced in this article. Five steps of evaluation model of fuzzy MCDM algorithms are then proposed to choose a best middle manager. Finally, an international shipping case is presented and the proposed fuzzy MCDM model is illustrated step by step. It can be seen from the demonstration that this evaluation model can be used to effectively select the best middle manager.
\end{abstract}

Key words: $\quad$ fuzzy evaluation model; multiple criteria decision-making (MCDM); middle manager; international shipping service provider

\section{Introduction}

The rise of international trade and the thriving marine transportation sector not only have accelerated the promotion and integration of the world economy and culture, but also created a vast market for the shipping industry [1]. International shipping is facing a competitive environment based on the four RCs, namely, rising complexity, rapid change, radical challenges, and rising competition. The competition among shipping companies is becoming more and more intense [2]. However, the services of shipping companies are no longer limited to port-to-port services. The emphasis is now on door-to-door services extending from seaside to landside [3], which has given birth to competition issues in business logistics and shipping markets.

With the fast development of international economic activities in recent years, the various operations of international trade are required to become increasingly economic and efficient. The integrated operations of international shipping logistics systems [4] could be 
regarded as an opportunity to strengthen international marketing. In addition, the growth of regional economies, the evolution of supply chain concepts, the progress of e-commerce, and the lifting of international financial and transportation controls have all contributed to the vigorous development of international logistics [1, 4]. In other words, with the development of international trade, many multinational companies have begun to use their companies as part of the layout of an international strategy that expects to achieve maximum profits through the international division of labour and production. Therefore, international shipping logistics has taken a pivotal role in global trade.

Due to increasingly fierce competition as well as diversified and rapid changes in international trade and shipping markets, how to provide customers with more comprehensive integrated logistics services is an important issue for international shipping service providers $[4,5]$. International shipping service providers play an important role of third-party logistics providers (3PLs) and are also important logistics supporters in the international transport industry [5]. Therefore, in order to provide better shipping logistics services and enhance companies operational performance so as to expand their scale, companies must continuously recruit excellent personnel through internal and external efforts, which can help form an effective work team and develop more effective organizations [6]. The shipping service industry requires employees who can create organizational business value externally. Therefore, firms must be able to see market opportunities and maintain close interaction with their customers so as to establish a good external network. Internally, they must be able to identify and integrate talents with relevant functions in order to grasp market opportunities.

Having excellent manpower quality is a key factor of a company's success [7]. Enterprise managers [6] can be divided into first-line, middle-level, and high-level managers, which have different responsibilities at different levels. For example, first-line managers supervise the work of non-management employees on a day-to-day basis and are among the front-line managers who perform tasks. Middle-level managers are responsible for overseeing first-line managers and are responsible for finding the best ways to align human resources and other resources to accomplish organizational goals. High-level managers are responsible for setting organizational goals, determining how different departments interact with each other, and supervising the performance of middle-level managers. Among the three types of managers mentioned above, middle-level managers act as a link between high level and firstline management. Moreover, they act as important information transmitters between the organizational operations department and the decision-making departments in task assignment as well as policy communication and organizational execution $[6,8,9]$. Therefore, choosing a middle-level manager with management competency and capabilities [10] will have a decisive influence on an organization's development.

The selection of a middle manager is important for organizational development. However, it is not easy to choose a good middle manager, because the human resources (HR) department is constantly faced with the uncertainty of the environment when choosing a middle manager and many evaluation criteria must be considered. Therefore, the selection process of a middle manager is full of the characteristics of multiple criteria decision-making (MCDM) [10]. In addition, with the changes of group decision-making and the environment, the weight value of each criterion and its importance also consists of fuzzy and changing characteristics [11]. Due to the ambiguity of traditional decision-making methods in dealing with the criteria weight and the inaccuracy of the transmission of decision-making information, it is unable to adequately express the information implied by various evaluation plans and decision-making criteria. In order to properly integrate the opinions of the decisionmaking groups (or committees) formed by the relevant decision-making units, and to evaluate and rank the alternatives for the best solution, this study intends to apply the fuzzy set theory [12] and incorporate MCDM to establish a selection model for a middle manager to allow 
international shipping service providers to find the best middle managers in a fuzzy environment.

The fuzzy MCDM method is valued by scholars in the decision making field and industrial circles and has been widely applied in numerous fields. In recent years, in terms of personnel selection, numerous studies [13-18] have adopted this evaluation method and it has received great attention from many human resource managers and scholars. Thus, this article will use the operation and concept of fuzzy MCDM to facilitate the evaluation of middle managers by applying this method. To sum up, the main purpose of this article is to construct a fuzzy evaluation model to facilitate the HR department of international shipping service providers to select the best middle managers. The following section introduces research methodology, and a fuzzy MCDM evaluation model is proposed in Section3. The fourth section illustrates a numerical example, and the conclusion is presented in Section 5.

\section{Methodology}

2.1 The trapezoidal fuzzy numbers and their algebraic operations

In a universe of discourse $X$, a fuzzy subset $\tilde{A}$ of $X$ is defined by a membership function $\mu_{\tilde{A}}(x)$, which maps each element $x$ in $X$ to a real number in the interval $[0,1]$. The function value $\mu_{\tilde{A}}(x)$ represents the grade of membership of $x$ in $\tilde{A}$.

A fuzzy number $\tilde{A}[19]$ in real line $\mathfrak{R}$ is a trapezoidal fuzzy number if its membership function $\mu_{\tilde{A}}: \mathfrak{R} \rightarrow[0,1]$ is

$$
\mu_{\tilde{A}}(x)=\left\{\begin{array}{lc}
\left(x-t^{c}\right) /\left(t^{a}-t^{c}\right), & t^{c} \leq x \leq t^{a} \\
1, & t^{a} \leq x \leq t^{b} \\
\left(x-t^{d}\right) /\left(t^{b}-t^{d}\right), & t^{b} \leq x \leq t^{d} \\
0, & \text { otherwise }
\end{array}\right.
$$

with $-\infty<t^{c} \leq t^{a} \leq t^{b} \leq t^{d}<\infty$. The trapezoidal fuzzy number can be denoted by $\left(t^{c}, t^{a}, t^{b}, t^{d}\right)$.

According to extension principle [12], let $\tilde{A}_{1}=\left(t^{c_{1}}, t^{a_{1}}, t^{b_{1}}, t^{d_{1}}\right)$ and $\tilde{A}_{2}=\left(t^{c_{2}}, t^{a_{2}}, t^{b_{2}}, t^{d_{2}}\right)$ be trapezoidal fuzzy numbers, the algebraic operations of any two trapezoidal fuzzy numbers $\tilde{A}_{1}$ and $\tilde{A}_{2}$ can be expressed as

(1) Fuzzy addition, $\oplus$ :

$$
\widetilde{A}_{1} \oplus \tilde{A}_{2}=\left(t^{c_{1}}+t^{c_{2}}, t^{a_{1}}+t^{a_{2}}, t^{b_{1}}+t^{b_{2}}, t^{d_{1}}+t^{d_{2}}\right) ;
$$

(2) Fuzzy subtraction, $\ominus$ :

$$
\tilde{A}_{1} \ominus \tilde{A}_{2}=\left(t^{c_{1}}-t^{d_{2}}, t^{a_{1}}-t^{b_{2}}, t^{b_{1}}-t^{a_{2}}, t^{d_{1}}-t^{c_{2}}\right) ;
$$

(3) Fuzzy multiplication, $\otimes$ :

$$
\begin{aligned}
& k \otimes \tilde{A}_{2}=\left(k t^{c_{2}}, k t^{a_{2}}, k t^{b_{2}}, k t^{d_{2}}\right), \quad k \in \Re, k \geq 0 ; \\
& \tilde{A}_{1} \otimes \tilde{A}_{2} \cong\left(t^{c_{1}} t^{c_{2}}, t^{a_{1}} t^{a_{2}}, t^{b_{1}} t^{b_{2}}, t^{d_{1}} t^{d_{2}}\right), \quad t^{c_{1}} \geq 0, \quad t^{c_{2}} \geq 0 ;
\end{aligned}
$$

(4) Fuzzy division, $\varnothing$ :

$$
\left(\tilde{A}_{1}\right)^{-1}=\left(t^{c_{1}}, t^{a_{1}}, t^{b_{1}}, t^{d_{1}}\right)^{-1} \cong\left(1 / t^{d_{1}}, 1 / t^{b_{1}}, 1 / t^{a_{1}}, 1 / t^{c_{1}}\right), \quad t^{c_{1}}>0 ;
$$




$$
\tilde{A}_{1} \varnothing \tilde{A}_{2} \cong\left(t^{c_{1}} / t^{d_{2}}, t^{a_{1}} / t^{b_{2}}, t^{b_{1}} / t^{a_{2}}, t^{d_{1}} / t^{c_{2}}\right), \quad t^{c_{1}} \geq 0, t^{c_{2}}>0 .
$$

\subsection{Linguistic variables}

Zadeh [20] proposed the concept of linguistic variables, which is used to deal with problems that are too complex or too difficult to be properly described by traditional quantitative methods. Linguistic variables can provide a convenient quantitative syntax for complex or poorly defined descriptions. A linguistic variable is a variable expressed in words or natural sentences. For example, "importance" is a linguistic variable in which its value is spoken language rather than numerical values. The approximate reasoning of the fuzzy set theory can be used to reasonably express the linguistic values of "very unimportant," "unimportant," "normal," "important," and "very important." In this article, the trapezoidal fuzzy number is used to convey the linguistic value of importance and superiority evaluation. For example, the linguistic value set of importance is $W=\{V L, L, M, H, V H\}$, while the linguistic value set of the superiority evaluation is $S=\{V P, P, F, G, V G\}$. The membership function for the linguistic values contained in the set $W$ and $S$ can be defined as follows: very low $(V L)=$ very poor $(V P)=(0,0,0.2,0.3)$; low $(L)=$ poor $(P)=(0.2,0.3,0.4,0.5)$; medium $(M)=$ fair $(F)=(0.4,0.5,0.6,0.7)$; high $(H)=\operatorname{good}(G)=(0.6,0.7,0.8,0.9)$; very high $(V H)$ $=$ very good $(V G)=(0.8,0.9,1,1)$. These trapezoidal fuzzy numbers can be referred to in Ghyym [21].

\subsection{Ranking fuzzy numbers with the maximizing and minimizing sets}

The ranking method developed by Chen [22], Kim and Park [23] and Chang and Chen [24] is adopted in this article, because it is easy and powerful.

Let $\tilde{A}_{i}, i=1,2, \ldots, n$, be the fuzzy numbers. The membership functions can be denoted by $\mu_{\tilde{A}_{i}}$. We define the maximizing set $\widetilde{G}=\left\{\left(x, \mu_{\widetilde{G}}(x)\right) \mid x \in R\right\}$ with

$$
\mu_{\widetilde{G}}(x)= \begin{cases}\left(x-x_{l}\right) /\left(x_{r}-x_{l}\right), & x \in\left[x_{l}, x_{r}\right], \\ 0, & \text { otherwise, }\end{cases}
$$

and the minimizing set $\tilde{L}=\left\{\left(x, \mu_{\tilde{L}}(x)\right) \mid x \in R\right\}$ with

$$
\mu_{\tilde{L}}(x)= \begin{cases}\left(x-x_{r}\right) /\left(x_{l}-x_{r}\right), & x \in\left[x_{l}, x_{r}\right], \\ 0, & \text { otherwise, }\end{cases}
$$

where $x_{l}=\inf D, x_{r}=\sup D, D=\bigcup_{i=1}^{n} D_{i}$ and $D_{i}=\left\{x \mid \mu_{\tilde{A}_{i}}(x)>0\right\}, i=1,2, \ldots, n$.

Then, the value of optimistic ranking (we can call the optimistic utility) $U_{\tilde{G}}^{O}\left(\tilde{A}_{i}\right)$ and the value of pessimistic ranking (we can call the pessimistic utility) $U_{\widetilde{L}}^{P}\left(\tilde{A}_{i}\right)$ of the fuzzy numbers $A_{i}$ can be denoted by

$$
U_{\widetilde{G}}^{O}\left(\tilde{A}_{i}\right)=\sup _{x}\left(\mu_{\widetilde{A}_{i}}(x) \wedge \mu_{\widetilde{G}}(x)\right)
$$

and

$$
U_{\tilde{L}}^{P}\left(\tilde{A}_{i}\right)=\sup _{x}\left(\mu_{\tilde{A}_{i}}(x) \wedge \mu_{\tilde{L}}(x)\right)
$$

where $\wedge$ means the minimum operation and $i=1,2, \ldots, n$. 
Finally, we define the ranking value $U_{T}^{R}\left(\tilde{A}_{i}\right)$ of fuzzy numbers $A_{i}$ as

$$
U_{T}^{R}\left(\tilde{A}_{i}\right)=\delta U_{\tilde{G}}^{O}\left(\tilde{A}_{i}\right)+(1-\delta) U_{\tilde{L}}^{P}\left(\tilde{A}_{i}\right), \quad 0 \leq \delta \leq 1 .
$$

The value of $\delta$ in the above formula is expressed as the total risk attitude index (TRAI) of the decision-makers (DMs), and TRAI reflects the risk-taking degree of the DMs. When $\delta<0.5$, the total risk attitude of the DMs is pessimistic, which indicates that the DMs are risk-averters. When $\delta=0.5$, the total risk attitude of the DMs is moderate, which indicates that the DMs are risk-neutral. When $\delta>0.5$, the total risk attitude of the DMs is optimistic, which indicates that the DMs are risk-lovers.

The TRAI of DMs is an important issue in group decision-making. Ghyym [21] compared the measurement methods of the risk attitude of DMs. In general, the value of $\delta$ can be determined in two ways. The first method is to determine the value of $\delta$ by a single DM in the data output stage [23] according to the risk-taking degree of his/her final subjective cognition. For example, the value of $\delta$ can be $0.24,0.5$ or 0.76 , etc. However, this approach is difficult to apply to problems in multi-person decision-making groups. Therefore, Chang and Chen [24] proposed another way of thinking. They believed that it is more reasonable for the value of $\delta$ to directly transmit the risk-taking degree of the group DMs at the data input stage. In this article, the method of Chang and Chen [24] is considered more reasonable after comprehensive consideration. Therefore, the method used to determine the value of $\delta$ developed by Chang and Chen [24] is the basis for evaluating the TRAI of the DMs or decision-making groups.

Furthermore, the ranking of the trapezoidal fuzzy numbers $\tilde{A}_{i}$ and $\tilde{A}_{j}$ are defined and based on the following rules:

(1) $\tilde{A}_{i}>\tilde{A}_{j} \Leftrightarrow U_{T}^{R}\left(\tilde{A}_{i}\right)>U_{T}^{R}\left(\tilde{A}_{j}\right)$;

(2) $\tilde{A}_{i}<\tilde{A}_{j} \Leftrightarrow U_{T}^{R}\left(\tilde{A}_{i}\right)<U_{T}^{R}\left(\tilde{A}_{j}\right)$;

(3) $\tilde{A}_{i}=\tilde{A}_{j} \Leftrightarrow U_{T}^{R}\left(\tilde{A}_{i}\right)=U_{T}^{R}\left(\tilde{A}_{j}\right)$.

Let $\tilde{A}_{i}=\left(t^{c_{i}}, t^{a_{i}}, t^{b_{i}}, t^{d_{i}}\right), i=1,2, \ldots, n$, be $n$ trapezoidal fuzzy numbers. By employed the Eq. (1), (2), (3) and (4), the ranking value $U_{T}^{R}\left(\tilde{A}_{i}\right)$ of the trapezoidal fuzzy number $A_{i}$ can be denoted by

$$
U_{T}^{R}\left(\tilde{A}_{i}\right)=\delta\left[\frac{t^{d_{i}}-x_{l}}{x_{r}-x_{l}-t^{b_{i}}+t^{d_{i}}}\right]+(1-\delta)\left[1-\frac{x_{r}-t^{c_{i}}}{x_{r}-x_{l}+t^{a_{i}}-t^{c_{i}}}\right],
$$

where $x_{l}=\min \left\{t^{c_{1}}, t^{c_{2}}, \ldots, t^{c_{n}}\right\}, x_{r}=\max \left\{t^{d_{1}}, t^{d_{2}}, \ldots, t^{d_{n}}\right\}$ and $0 \leq \delta \leq 1$.

After obtaining the value of $\delta$, the ranking value of Eq. (5) can be calculated, and according to the above ranking rules, the priority of the $n$ trapezoidal fuzzy numbers can be determined.

\section{The fuzzy evaluation model}

A complete evaluation model of MCDM should include goals or objectives, alternatives, criteria or attributes, performance values, and the DMs' preferences, etc. Based on this, the operational steps of the fuzzy evaluation model for an international shipping service provider 
Ji-Feng Ding, Jung-Fong Kuo, Wen-Hui Tai
A fuzzy evaluation model of choosing a middle manager for an international shipping service provider

to select a middle manager in this article mainly includes five steps, which are explained as follows.

Step 1: Create a hierarchical structure.

Step 2: Obtain fuzzy weights for all criteria and sub-criteria.

Step 3: Evaluate the fuzzy ratings of all alternatives against all evaluation criteria.

Step 4: Evaluate comprehensive evaluation values for all alternatives.

Step 5: Select the best solution.

In order to allow readers to clearly understand the operational process of the model in this article, the flow chart of the fuzzy evaluation model is shown in Fig. 1.

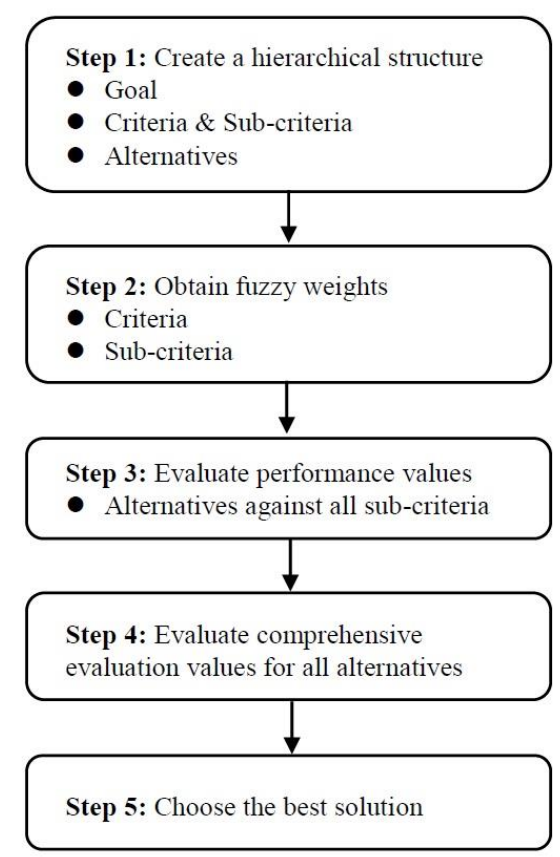

Fig. 1 The flow chart of the proposed fuzzy evaluation model

\subsection{Create a hierarchical structure}

Because the hierarchical structure is the skeleton structure of the system, the primary task of the MCDM is to establish a structure of decision-making issues so that the relationships between different hierarchical structures can be systematically understood. The hierarchical structure of this article is shown in Fig. 2. In this architecture, tier 1 is the goal, and it is expected that the best one can be selected among the middle managers under evaluation; tier 2 is the $k$ main criteria for the selection; tier 3 is the $n_{1}+\cdots+n_{p}+\cdots+n_{k}$ subcriteria for all main criteria; and tier 4 are the $m$ alternatives.

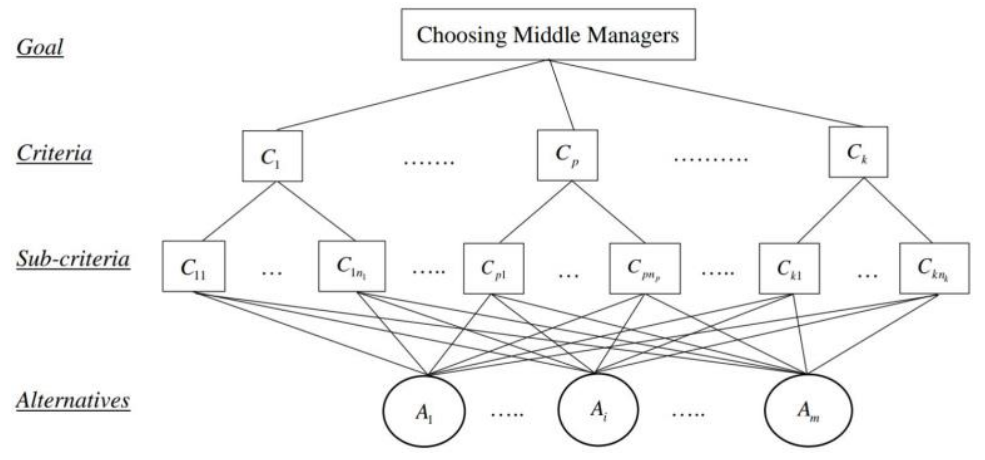

Fig. 2 Hierarchy structure of choosing middle managers 
In terms of the selection criteria and sub-criteria, because the factors influencing the selection of middle managers involve the skills, capabilities and competency of managers, based on the related management academic literature [4-10, 25-28] and the opinions of the heads of the HR departments in international shipping companies and management scholars, five assessment aspects and 20 assessment criteria are summed up in this article (their codes are marked in parentheses). The criteria and sub-criteria in this article are all subjective criteria.

(1) Leadership Competency $\left(C_{1}\right)$. This assessment aspect includes four management capabilities, including 'the capability to effectively build team spirit and work atmosphere $\left(C_{11}\right)$,' 'the capability to positively motivate subordinates $\left(C_{12}\right)$,' 'the capability to influence subordinates to support the team $\left(C_{13}\right)$,' and 'the capability to impartially and objectively evaluate the performance of subordinates $\left(C_{14}\right)$.'

(2) Interpersonal Competency $\left(C_{2}\right)$. This assessment aspect includes four management capabilities, including 'the capability to integrate and coordinate $\left(C_{21}\right)$,' 'the capability to lead team awareness $\left(C_{22}\right)$,' 'the capability to communicate in spoken language $\left(C_{23}\right)$,' and 'the capability to manage interpersonal networks perfectly $\left(C_{24}\right)$.'

(3) Administrative Competency $\left(C_{3}\right)$. This assessment aspect includes four management capabilities, including 'the capability to effectively interpret relevant administrative information $\left(C_{31}\right)$,' 'the capability to manage crisis $\left(C_{32}\right)$,' 'the capability to transform conceptual schemes into executable strategic plans $\left(C_{33}\right)$,' and 'the capability to effectively manage and allocate available resources $\left(C_{34}\right)$.'

(4) Professional Competency $\left(C_{4}\right)$. This assessment aspect includes four management capabilities, including 'the capability to thoroughly understand the work procedures of logistics and related practices $\left(C_{41}\right)$,' 'the capability to manage work pressure $\left(C_{42}\right)$,' 'the capability to use logistics expertise to enhance work efficiency $\left(C_{43}\right)$,' and 'the capability to have cross-divisional work experience $\left(C_{44}\right)$.'

(5) Conceptual Competency $\left(C_{5}\right)$. This assessment aspect includes four management capabilities, including 'the capability to simplify complex issues $\left(C_{51}\right)$,' 'the capability to integrate resources within and outside related organizations $\left(C_{52}\right)$,' 'the capability to plan and organize $\left(C_{53}\right)$,' and 'the capability to properly understand the internal and external competitive environment $\left(C_{54}\right)$.'

\subsection{Obtain fuzzy weights for all criteria and sub-criteria}

The concept of linguistic variables in Section 2.2 is used to assist in the calculation of fuzzy weights. In this article, the fuzzy weights of all criteria and sub-criteria are obtained by using the arithmetic mean.

Let $\quad \tilde{w}_{p h}=\left(t^{c_{p h}}, t^{a_{p h}}, t^{b_{p h}}, t^{d_{p h}}\right), \quad 0 \leq t^{c_{p h}} \leq t^{a_{p h}} \leq t^{b_{p h}} \leq t^{d_{p h}} \leq 1, \quad p=1,2, \ldots, k ; \quad$ and $h=1,2, \ldots, n$, represent the fuzzy weight given to the evaluation criterion $C_{p}$ by decision maker $D_{h}$. According to Zadeh's extension principle [12], the average fuzzy weight of the evaluation criterion $C_{p}$ can then be represented by

$$
\tilde{W}_{p}=1 / n \otimes\left(\tilde{w}_{p 1} \oplus \tilde{w}_{p 2} \oplus \cdots \oplus \tilde{w}_{p n}\right)=\left(t^{c_{p}}, t^{a_{p}}, t^{b_{p}}, t^{d_{p}}\right)
$$

where $t^{c_{p}}=\frac{1}{n} \sum_{h=1}^{n} t^{c_{p h}}, t^{a_{p}}=\frac{1}{n} \sum_{h=1}^{n} t^{a_{p h}}, t^{b_{p}}=\frac{1}{n} \sum_{h=1}^{n} t^{b_{p h}}, t^{d_{p}}=\frac{1}{n} \sum_{h=1}^{n} t^{d_{p h}}$. 
Let $\quad \tilde{w}_{p j h}=\left(t^{c_{p j h}}, t^{a_{p j h}}, t^{b_{p j h}}, t^{d_{p j h}}\right), \quad 0 \leq t^{c_{p j h}} \leq t^{a_{p j h}} \leq t^{b_{p j h}} \leq t^{d_{p j h}} \leq 1, \quad p=1,2, \ldots, k ;$ $j=1,2, \ldots, n_{p} ; h=1,2, \ldots, n$, represent the fuzzy weight given to the evaluation sub-criterion $C_{p j}$ by decision maker $D_{h}$. According to Zadeh's extension principle [12], the average fuzzy weight of evaluation sub-criterion $C_{p j}$ can then be represented by

$$
\tilde{W}_{p j}=1 / n \otimes\left(\tilde{w}_{p j 1} \oplus \tilde{w}_{p j 2} \oplus \cdots \oplus \tilde{w}_{p j n}\right)=\left(t^{c_{p j}}, t^{a_{p j}}, t^{b_{p j}}, t^{d_{p j}}\right),
$$

where $t^{c_{p j}}=\frac{1}{n} \sum_{h=1}^{n} t^{c_{p j h}}, t^{a_{p j}}=\frac{1}{n} \sum_{h=1}^{n} t^{a_{p j h}}, t^{b_{p j}}=\frac{1}{n} \sum_{h=1}^{n} t^{b_{p j h}}, t^{d_{p j}}=\frac{1}{n} \sum_{h=1}^{n} t^{d_{p j h}}$.

\subsection{Evaluate the fuzzy ratings of all alternatives against all evaluation criteria}

In terms of the evaluation of the performance value, the arithmetic mean and the concept of linguistic variables are still used to calculate the appropriateness rating in this study.

Let $\quad \tilde{s}_{i p j h}=\left(t^{c_{i j j h}}, t^{a_{i j j h}}, t^{b_{i j j h}}, t^{d_{i j h h}}\right), \quad 0 \leq t^{c_{i j j h}} \leq t^{a_{i j j h}} \leq t^{b_{i j h h}} \leq t^{d_{i j j h}} \leq 1, \quad i=1,2, \ldots, m ;$ $p=1,2, \ldots, k ; j=1,2, \ldots, n_{p} ;$ and $h=1,2, \ldots, n$, represent the appropriateness rating assigned to alternative $A_{i}$ by decision maker $D_{h}$ for the evaluation sub-criterion $C_{p j}$. According to Zadeh's extension principle [12], the average fuzzy appropriateness rating of alternative $A_{i}$ can then be represented by

$$
\tilde{S}_{i p j}=1 / n \otimes\left(\tilde{s}_{i p j 1} \oplus \tilde{s}_{i p j 2} \oplus \cdots \oplus \tilde{s}_{i p j n}\right)=\left(t^{c_{i p j}}, t^{a_{i p j}}, t^{b_{i p j}}, t^{d_{i p j}}\right),
$$

where $t^{c_{i p j}}=\frac{1}{n} \sum_{h=1}^{n} t^{c_{i j j h}}, t^{a_{i p j}}=\frac{1}{n} \sum_{h=1}^{n} t^{a_{i p j h}}, t^{b_{i j j}}=\frac{1}{n} \sum_{h=1}^{n} t^{b_{i p j h}}$, and $t^{d_{i p j}}=\frac{1}{n} \sum_{h=1}^{n} t^{d_{i j j h}}$.

\subsection{Evaluate comprehensive evaluation values for all alternatives}

Let $\tilde{W}_{p}=\left(t^{c_{p}}, t^{a_{p}}, t^{b_{p}}, t^{d_{p}}\right), \quad p=1,2, \ldots, k$, be the average fuzzy weight of the evaluation criterion $C_{p}$. Let $\tilde{W}_{p j}=\left(t^{c_{p j}}, t^{a_{p j}}, t^{b_{p j}}, t^{d_{p j}}\right), \quad p=1,2, \ldots, k ; j=1,2, \ldots, n_{p}$, be the average fuzzy weight of the evaluation sub-criterion $C_{p j}$. Let $\tilde{S}_{i p j}=\left(t^{c_{i j j}}, t^{a_{i p j}}, t^{b_{i j j}}, t^{d_{i j j}}\right)$, $i=1,2, \ldots, m ; p=1,2, \ldots, k ; j=1,2, \ldots, n_{p}$, be the average fuzzy appropriateness rating of alternative $A_{i}$. Then, the aggregation appropriateness ratings of the $n_{p}$ evaluation subcriteria under the $p^{\text {th }}$ evaluation criterion for the $i^{\text {th }}$ alternative, can then be represented by $\tilde{R}_{i p}$. That is:

$$
\begin{aligned}
& \tilde{R}_{i p}=\frac{1}{n_{p}} \otimes\left[\left(\tilde{S}_{i p 1} \otimes \tilde{W}_{p 1}\right) \oplus\left(\tilde{S}_{i p 2} \otimes \tilde{W}_{p 2}\right) \oplus \cdots \oplus\left(\tilde{S}_{i p j} \otimes \tilde{W}_{p j}\right) \oplus \cdots \oplus\left(\tilde{S}_{i p n_{p}} \otimes \tilde{W}_{p n_{p}}\right)\right] \\
& p=1,2, \ldots, k ; i=1,2, \ldots, m .
\end{aligned}
$$

According to the extension principle, we can represent $\widetilde{R}_{i p}$ as $\widetilde{R}_{i p} \cong\left(t^{Y_{i p}}, t^{Q_{i p}}, t^{G_{i p}}, t^{Z_{i p}}\right)$, where $t^{Y_{i p}}=\sum_{j=1}^{n_{p}} t^{c_{i j j}} t^{c_{p j}} / n_{p}, \quad t^{Q_{i p}}=\sum_{j=1}^{n_{p}} t^{a_{i j j}} t^{a_{p j}} / n_{p}, \quad t^{Y_{i p}}=\sum_{j=1}^{n_{p}} t^{c_{i j j}} t^{c_{p j}} / n_{p}, \quad t^{Y_{i p}}=\sum_{j=1}^{n_{p}} t^{c_{i j j}} t^{c_{p j}} / n_{p}$, for $i=1,2, \ldots, m ; \quad p=1,2, \ldots, k$. 
Similarly, the aggregation appropriateness ratings of the $k$ evaluation criteria for the $i^{t h}$ alternative can be represented by $\tilde{F}_{i}$. That is:

$$
\begin{aligned}
\tilde{F}_{i}= & \frac{1}{k} \otimes\left[\left(\tilde{R}_{i 1} \otimes \tilde{W}_{1}\right) \oplus\left(\tilde{R}_{i 2} \otimes \tilde{W}_{2}\right) \oplus \cdots \oplus\left(\tilde{R}_{i p} \otimes \tilde{W}_{p}\right) \oplus \cdots \oplus\left(\tilde{R}_{i k} \otimes \tilde{W}_{k}\right)\right], \\
& i=1,2, \ldots, m .
\end{aligned}
$$

According to the extension principle, we can represent $\tilde{F}_{i}$ as $\tilde{F}_{i} \cong\left(t^{Y_{i}}, t^{Q_{i}}, t^{G_{i}}, t^{Z_{i}}\right)$, where $\quad t^{Y_{i}}=\sum_{p=1}^{k} t^{Y_{i p}} t^{c_{p}} / k, \quad t^{Q_{i}}=\sum_{p=1}^{k} t^{Q_{\text {ip }}} t^{a_{p}} / k, \quad t^{G_{i}}=\sum_{p=1}^{k} t^{G_{\text {ip }}} t^{b_{p}} / k, \quad t^{Z_{i}}=\sum_{p=1}^{k} t^{Z_{\text {ip }}} t^{b_{p}} / k, \quad$ for $i=1,2, \ldots, m$.

\subsection{Select the best solution}

Based on the ranking method in Section 2.3, for the aggregation appropriateness ratings $\tilde{F}_{i}$ in the above alternatives, the ranking value $U_{T}^{R}\left(\tilde{F}_{i}\right)$ can be represented as:

$$
U_{T}^{R}\left(\tilde{F}_{i}\right)=\delta\left[\frac{t^{Z_{i}}-x_{l}}{x_{r}-x_{l}-t^{G_{i}}+t^{Z_{i}}}\right]+(1-\delta)\left[1-\frac{x_{r}-t^{Y_{i}}}{x_{r}-x_{l}+t^{Q_{i}}-t^{Y_{i}}}\right],
$$

where $i=1,2, \ldots, m, x_{l}=\min \left\{t^{Y_{1}}, t^{Y_{2}}, \ldots, t^{Y_{m}}\right\}, x_{r}=\max \left\{t^{Z_{1}}, t^{Z_{2}}, \ldots, t^{Z_{m}}\right\}$, and $0 \leq \delta \leq 1$.

The TRAI of the DMs in Eq. (11), i.e., the value of $\delta$, must be obtained. According to Section 2.3, the information of the data input stage [24] is used to determine the value of $\delta$. Therefore, according to the fuzzy MCDM model developed in this article (Section 3.2 to 3.4), the value of $\delta$ of TRAI can be represented as:

$$
\delta=\frac{\delta_{W_{1}}+\delta_{W_{2}}+\delta_{S}}{(k \times n)+\left(n \times \sum_{p=1}^{k} n_{p}\right)+\left(m \times n \times \sum_{p=1}^{k} n_{p}\right)},
$$

where

$$
\begin{aligned}
\delta_{W_{1}} & =\sum_{p=1}^{k} \sum_{h=1}^{n}\left(\frac{t^{a_{p h}}-t^{c_{p h}}}{\left(t^{d_{p h}}-t^{b_{p h}}\right)+\left(t^{a_{p h}}-t^{c_{p h}}\right)}\right), \\
\delta_{W_{2}} & =\sum_{p=1}^{k} \sum_{j=1}^{n_{p}} \sum_{h=1}^{n}\left(\frac{t^{a_{p j h}}-t^{c_{p j h}}}{\left(t^{d_{p j h}}-t^{b_{p j h}}\right)+\left(t^{a_{p j h}}-t^{c_{p j h}}\right)}\right),
\end{aligned}
$$

and

$$
\delta_{S}=\sum_{i=1}^{m} \sum_{p=1}^{k} \sum_{j=1}^{n_{p}} \sum_{h=1}^{n}\left(\frac{t^{a_{i j / h}}-t^{c_{i j h h}}}{\left(t^{d_{i j h h}}-t^{b_{i j p h}}\right)+\left(t^{a_{i j, h}}-t^{c_{i j h}}\right)}\right) .
$$

Finally, based on Eq. (11) and (12), the final ranking values $U_{T}^{R}\left(\tilde{F}_{i}\right)$ of $m$ alternatives can be calculated. Therefore, the decision-making committee will determine the best alternative based on the ranking rules in Section 2.3. 


\section{The numerical illustration}

In this section, a hypothetical case is taken as an example to illustrate the fuzzy MCDM selection model proposed in this study. The operational process is described as follows.

Step 1. Assume that the HR department of an international shipping company intends to promote one middle manager in the operation department. There are three experts, $A, B$, and $C$, who form a selection panel to select the best manager among the $X, Y$, and $Z$ middle manager candidates. The selection criteria for this case are based on the five main criteria and 20 sub-criteria described in Section 3.1.

Table 1 The fuzzy weights of all criteria and sub-criteria

\begin{tabular}{|c|c|c|c|c|c|c|c|}
\hline $\begin{array}{c}\text { Criteria / } \\
\text { Sub-criteria }\end{array}$ & DMs & LVs & Fuzzy weights & $\begin{array}{c}\text { Criteria / } \\
\text { Sub-criteria }\end{array}$ & DMs & LVs & Fuzzy weights \\
\hline \multirow{3}{*}{$C_{1}$} & $A$ & $H$ & \multirow{3}{*}{$\begin{array}{c}(0.667,0.767,0.867 \\
0.933)\end{array}$} & \multirow{3}{*}{$C_{31}$} & $A$ & $H$ & \multirow{3}{*}{$\begin{array}{c}(0.40,0.50,0.60 \\
0.70)\end{array}$} \\
\hline & $B$ & $H$ & & & $B$ & $L$ & \\
\hline & $C$ & $V H$ & & & $C$ & $M$ & \\
\hline \multirow{3}{*}{$C_{2}$} & $A$ & $M$ & \multirow{3}{*}{$\begin{array}{c}(0.60,0.70,0.80, \\
0.867)\end{array}$} & \multirow{3}{*}{$C_{32}$} & $A$ & $\mathrm{VH}$ & \multirow{3}{*}{$\begin{array}{c}(0.667,0.767,0.867 \\
0.90)\end{array}$} \\
\hline & $B$ & $\mathrm{VH}$ & & & $B$ & $M$ & \\
\hline & $C$ & $H$ & & & $C$ & VH & \\
\hline \multirow{3}{*}{$C_{3}$} & $A$ & $M$ & \multirow{3}{*}{$\begin{array}{c}(0.533,0.633,0.733 \\
0.80)\end{array}$} & \multirow{3}{*}{$C_{33}$} & $A$ & $M$ & \multirow{3}{*}{$\begin{array}{c}(0.533,0.633,0.733 \\
0.833)\end{array}$} \\
\hline & $B$ & $\mathrm{VH}$ & & & $\boldsymbol{B}$ & $H$ & \\
\hline & $C$ & $M$ & & & $C$ & $H$ & \\
\hline \multirow{3}{*}{$C_{4}$} & $A$ & $H$ & \multirow{3}{*}{$\begin{array}{c}(0.667,0.767,0.867 \\
0.933)\end{array}$} & \multirow{3}{*}{$C_{34}$} & $A$ & $L$ & \multirow{3}{*}{$\begin{array}{c}(0.267,0.367,0.467 \\
0.567)\end{array}$} \\
\hline & $B$ & $\mathrm{VH}$ & & & $\boldsymbol{B}$ & $M$ & \\
\hline & $C$ & $H$ & & & $C$ & $L$ & \\
\hline \multirow{3}{*}{$C_{5}$} & $A$ & $H$ & \multirow{3}{*}{$\begin{array}{c}(0.533,0.633,0.733 \\
0.833)\end{array}$} & \multirow{3}{*}{$C_{41}$} & $A$ & $H$ & \multirow{3}{*}{$\begin{array}{c}(0.467,0.567,0.667 \\
0.767)\end{array}$} \\
\hline & $B$ & $H$ & & & $B$ & $M$ & \\
\hline & $C$ & $M$ & & & $C$ & $M$ & \\
\hline \multirow{3}{*}{$C_{11}$} & $A$ & $M$ & \multirow{3}{*}{$\begin{array}{c}(0.667,0.767,0.867 \\
0.90)\end{array}$} & \multirow{3}{*}{$C_{42}$} & $A$ & $M$ & \multirow{3}{*}{$\begin{array}{c}(0.533,0.633,0.733 \\
0.833)\end{array}$} \\
\hline & B & $V H$ & & & $\boldsymbol{B}$ & $H$ & \\
\hline & $C$ & $\mathrm{VH}$ & & & $C$ & $H$ & \\
\hline \multirow{3}{*}{$C_{12}$} & $A$ & $M$ & & & $A$ & $H$ & \\
\hline & $B$ & $L$ & $\begin{array}{c}(0.333,0.433,0.533 \\
0.633)\end{array}$ & $C_{43}$ & $B$ & $M$ & $(0.46 \%, 0.56 \%, 0.66 \%$ \\
\hline & $C$ & $M$ & & & $C$ & $M$ & \\
\hline & $A$ & $V H$ & & & $A$ & $\mathrm{VH}$ & \\
\hline$C_{13}$ & $B$ & $H$ & $(0.60,0.70,0.80$ & $C_{44}$ & $B$ & $H$ & $(0.66 \%, 0.76 \%, 0.86 \%$ \\
\hline & $C$ & $M$ & & & $C$ & $H$ & \\
\hline & $A$ & $M$ & & & $A$ & $\mathrm{VH}$ & \\
\hline$C_{14}$ & $B$ & $M$ & $\begin{array}{c}(0.533,0.633,0.733, \\
080)\end{array}$ & $C_{51}$ & $B$ & $V H$ & $(0.733,0.833,0.933$ \\
\hline & $C$ & $V H$ & & & $C$ & $H$ & \\
\hline & $A$ & $M$ & & & $A$ & $H$ & \\
\hline$C_{21}$ & $\boldsymbol{B}$ & $H$ & $(0.40,0.50,0.60,0.70)$ & $C_{52}$ & $\boldsymbol{B}$ & $L$ & $(0.40,0.50,0.60$ \\
\hline & $C$ & $L$ & & & $C$ & $M$ & \\
\hline & $A$ & $M$ & & & $A$ & $V H$ & \\
\hline$C_{22}$ & $B$ & $M$ & $(0.40,0.50,0.60,0.70)$ & $C_{53}$ & $B$ & $M$ & $(0.667,0.767,0.867$, \\
\hline & $C$ & $M$ & & & $C$ & $V H$ & \\
\hline & $A$ & $M$ & & & $A$ & $H$ & \\
\hline$C_{23}$ & $\boldsymbol{B}$ & $H$ & $(0.533,0.633,0.733$ & $C_{54}$ & $B$ & $\mathrm{VH}$ & $(0.60,0.70,0.80$ \\
\hline & $C$ & $H$ & & & $C$ & $M$ & \\
\hline & $A$ & $V H$ & & & & & \\
\hline$C_{24}$ & $B$ & $M$ & $(0.60,0.70,0.80$ & & & & \\
\hline & $C$ & $H$ & & & & & \\
\hline
\end{tabular}


Table 2 The fuzzy ratings of three candidates against all evaluation sub-criteria

\begin{tabular}{|c|c|c|c|c|c|c|c|}
\hline \multirow{2}{*}{ Sub-criteria } & \multirow{2}{*}{ DMs } & \multicolumn{3}{|c|}{ LVs } & \multicolumn{3}{|c|}{ Performance values } \\
\hline & & $X$ & $Y$ & $Z$ & $X$ & $Y$ & $Z$ \\
\hline \multirow{3}{*}{$C_{11}$} & $A$ & $P$ & $G$ & $P$ & \multirow{3}{*}{$\begin{array}{c}(0.20,0.267 \\
0.40,0.50)\end{array}$} & \multirow{3}{*}{$\begin{array}{l}(0.733,0.833 \\
0.933,0.967)\end{array}$} & \multirow{3}{*}{$\begin{array}{c}(0.133,0.20, \\
0.333,0.433)\end{array}$} \\
\hline & $\boldsymbol{B}$ & $V P$ & $V G$ & $V P$ & & & \\
\hline & $C$ & $F$ & $V G$ & $P$ & & & \\
\hline \multirow{3}{*}{$C_{12}$} & $A$ & $V P$ & $V G$ & $V P$ & \multirow{3}{*}{$\begin{array}{c}(0.20,0.233 \\
0.40,0.50)\end{array}$} & \multirow{3}{*}{$\begin{array}{c}(0.733,0.833 \\
0.933,0.967)\end{array}$} & \multirow{3}{*}{$(0,0,0.20,0.30)$} \\
\hline & $\boldsymbol{B}$ & $G$ & $G$ & $V P$ & & & \\
\hline & $C$ & $V P$ & $V G$ & $V P$ & & & \\
\hline \multirow{3}{*}{$C_{13}$} & $A$ & $P$ & $P$ & $P$ & \multirow{3}{*}{$\begin{array}{l}(0.267,0.333 \\
0.467,0.567)\end{array}$} & \multirow{3}{*}{$\begin{array}{c}(0.267,0.333 \\
0.467,0.567)\end{array}$} & \multirow{3}{*}{$\begin{array}{c}(0.267,0.333 \\
0.467,0.567)\end{array}$} \\
\hline & $\boldsymbol{B}$ & $G$ & $G$ & $G$ & & & \\
\hline & $C$ & $V P$ & $V P$ & $V P$ & & & \\
\hline \multirow{3}{*}{$C_{14}$} & $A$ & $F$ & $G$ & $P$ & \multirow{3}{*}{$\begin{array}{c}(0.60,0.70,0.80 \\
0.867)\end{array}$} & & \\
\hline & $\boldsymbol{B}$ & $G$ & $G$ & $P$ & & $(0.66 \%, 0.76 \%$ & $(0.40,0.50,0.60$ \\
\hline & $C$ & $V G$ & $V G$ & $V G$ & & & \\
\hline & $A$ & $G$ & $G$ & $G$ & & & \\
\hline$C_{21}$ & $\boldsymbol{B}$ & $V G$ & $V G$ & $V G$ & $(0.533,0.633$ & $(0.533,0.633$ & $(0.533,0.633$ \\
\hline & $C$ & $P$ & $P$ & $P$ & & & \\
\hline & $A$ & $G$ & $V G$ & $V P$ & & & \\
\hline$C_{22}$ & $\boldsymbol{B}$ & $G$ & $G$ & $V P$ & $(0.467,0.567$, & $(0.733,0.833$, & (0.067, 0.10, \\
\hline & $C$ & $P$ & $V G$ & $P$ & & $0.933,0.90 /)$ & \\
\hline & $A$ & $F$ & $F$ & $F$ & & & \\
\hline$C_{23}$ & $B$ & $F$ & $F$ & $V P$ & $\begin{array}{c}(0.40,0.50,0.00, \\
070)\end{array}$ & $\begin{array}{c}(0.40,0.50,0.00, \\
0.70)\end{array}$ & (0.20\%, 0.353 \\
\hline & $C$ & $F$ & $F$ & $F$ & & & \\
\hline & $A$ & $P$ & $P$ & $P$ & & & \\
\hline$C_{24}$ & $B$ & $F$ & $F$ & $P$ & $0.40,0.50)$ & $06670733)$ & (0.153, 0.20, \\
\hline & $C$ & $V P$ & $V G$ & $V P$ & & & \\
\hline & $A$ & $F$ & $F$ & $V P$ & & & \\
\hline$C_{31}$ & $B$ & $V P$ & $V P$ & $P$ & (0.535, 0.40, & (0.535, 0.40, & (0.20\%, 0.533, \\
\hline & $C$ & $G$ & $G$ & $G$ & & & \\
\hline & $A$ & $G$ & $G$ & $G$ & & & \\
\hline$C_{32}$ & $\boldsymbol{B}$ & $V G$ & $V G$ & $V G$ & $\begin{array}{c}(0.00,0.10,0.00, \\
0.867)\end{array}$ & $0.933,0.967)$ & $0.867)$ \\
\hline & $C$ & $F$ & $V G$ & $F$ & & & \\
\hline & $A$ & $P$ & $P$ & $P$ & & & \\
\hline$C_{33}$ & $\boldsymbol{B}$ & $P$ & $V G$ & $V P$ & $(0.40,0.50,0.60$, & $(0.60,0 . / 0,0.80$ & $(0.06 /, 0.1,0.26 /$, \\
\hline & $C$ & $V G$ & $V G$ & $V P$ & & & \\
\hline & $A$ & $V P$ & $V G$ & $V P$ & & & \\
\hline$C_{34}$ & $\boldsymbol{B}$ & $G$ & $G$ & $G$ & (0.20\%, 0.353 & (0.753, 0.853, & $\begin{array}{l}(0.201,0.535, \\
0.4670567)\end{array}$ \\
\hline & $C$ & $P$ & $V G$ & $P$ & & & \\
\hline & $\boldsymbol{A}$ & $G$ & $G$ & $V P$ & & & \\
\hline$C_{41}$ & $\boldsymbol{B}$ & $F$ & $G$ & $F$ & $(0.60,0 . / 0,0.80$, & $(0.66 /, 0 . / 6 /$, & $(0.40,0.46 /, 0.60$ \\
\hline & $C$ & $V G$ & $V G$ & $V G$ & & & \\
\hline & $A$ & $F$ & $G$ & $F$ & & & \\
\hline$C_{42}$ & $\boldsymbol{B}$ & $V G$ & $V G$ & $V P$ & $(0.60,0.70,0.80$ & $(0.133,0.833$, & $(0.20,0.26 /, 0.40$ \\
\hline & $C$ & $G$ & $V G$ & $P$ & & & \\
\hline & $A$ & $V G$ & $V G$ & $V G$ & & & \\
\hline$C_{43}$ & $\boldsymbol{B}$ & $P$ & $V G$ & $P$ & $(0.40,0.50,0.60$ & (0.733, 0.833, & (0.333, 0.40 , \\
\hline & $C$ & $P$ & $G$ & $V P$ & & & \\
\hline & $A$ & $P$ & $V G$ & $P$ & & & \\
\hline$C_{44}$ & $\boldsymbol{B}$ & $F$ & $F$ & $P$ & $(0.20,0.26 /$, & $(0.40,0.46 /$, & $(0.133,0.2,0.333$, \\
\hline & $C$ & $V P$ & $V P$ & $V P$ & & & \\
\hline & $A$ & $F$ & $V G$ & $F$ & & & \\
\hline$C_{51}$ & $\boldsymbol{B}$ & $V G$ & $G$ & $V G$ & (0.533, 0.633, & $(0.133,0.833$, & (0.533, 0.633, \\
\hline & $C$ & $F$ & $V G$ & $F$ & & & \\
\hline$C_{52}$ & $A$ & $G$ & $G$ & $G$ & $(0.60,0.70,0.80$ & $(0.60,0.70,0.80$ & $(0.267,0.333$ \\
\hline
\end{tabular}




\begin{tabular}{|c|c|c|c|c|c|c|c|}
\hline \multirow{5}{*}{$C_{53}$} & $\boldsymbol{B}$ & $G$ & $G$ & $V P$ & $0.90)$ & $0.90)$ & $0.467,0.567)$ \\
\cline { 2 - 5 } & $\boldsymbol{C}$ & $G$ & $G$ & $P$ & & & \\
\hline & $\boldsymbol{A}$ & $V P$ & $V G$ & $P$ & \multirow{2}{*}{$(0.267,0.333}$, & $(0.733,0.833$, & $(0.133,0.20$, \\
\cline { 2 - 5 } & $\boldsymbol{B}$ & $G$ & $V G$ & $P$ & $0.467,0.567)$ & $0.933,0.967)$ & $0.333,0.433)$ \\
\cline { 2 - 5 }$C_{54}$ & $\boldsymbol{C}$ & $P$ & $G$ & $V P$ & & & \\
& $\boldsymbol{A}$ & $V G$ & $V G$ & $V G$ & \multirow{2}{*}{$0.467,0.567}$, & $(0.467,0.567$, & $(0.333,0.40$, \\
\cline { 2 - 5 } & $\boldsymbol{B}$ & $P$ & $P$ & $P$ & $0.667,0.733)$ & $0.667,0.733)$ & $0.533,0.60)$ \\
\cline { 2 - 5 } & $\boldsymbol{C}$ & $F$ & $F$ & $V P$ & & & \\
\hline
\end{tabular}

Step 2. The three experts use the linguistic variables of Section 2.2 to evaluate the importance of the five main criteria and 20 sub-criteria, and then use the formula of Section 3.2 to obtain the fuzzy weights. The results are shown in Table 1. In addition, the three experts use the same method to evaluate the fuzzy ratings of all alternatives against all evaluation sub-criteria and use the formula of Section 3.3 to obtain the appropriateness rating. The results are shown in Table 2 .

Step 3. Based on Eq. (9), the aggregation appropriateness ratings of the three candidates versus all evaluation sub-criteria can be obtained. The results are shown in Table 3. Furthermore, based on Eq. (10), we can obtain the final aggregation appropriateness ratings of the three candidates. The results are shown in Table 4.

Table 3 The aggregation ratings of three candidates versus all evaluation sub-criteria

\begin{tabular}{|c|c|c|c|c|c|}
\hline$\tilde{R}_{X 1}$ & $(0.170,0.2455,0.380$, & $\tilde{R}_{Y 1}$ & $(0.3122,0.4296,0.5788$, & $\tilde{R}_{Z 1}$ & $(0.1155,0.1758,0.3022$, \\
\hline$\tilde{R}_{X 2}$ & $(0.1833,0.2759,0.40$, & $\tilde{R}_{Y 2}$ & $(0.250,0.3616,0.4933$, & $\tilde{R}_{Z 2}$ & $(0.1155,0.1793,0.3022$, \\
\hline$\tilde{R}_{X 3}$ & $0.5284)$ & $0.6139)$ & $0.4162)$ \\
\hline$\tilde{R}_{X 4}$ & $(0.2045,0.2939,0.4178$, & $\tilde{R}_{Y 3}$ & $(0.2844,0.3969,0.5377$, & $\tilde{R}_{Z 3}$ & $(0.1535,0.2222,0.3469$, \\
\hline$\tilde{R}_{X 5}$ & $0.5251)$ & $0.6389)$ & $0.4511)$ \\
\hline
\end{tabular}

Table 4 The final aggregation appropriateness ratings of the three candidates

\begin{tabular}{|c|c|}
\hline$\tilde{F}_{X}$ & $(0.1016,0.1772,0.2978,0.4283)$ \\
\hline$\tilde{F}_{Y}$ & $(0.1507,0.2510,0.3936,0.5308)$ \\
\hline$\tilde{F}_{Z}$ & $(0.0675,0.1218,0.2306,0.3447)$ \\
\hline
\end{tabular}

Step 4. Based on Eq. (12), we can obtain the TRAI of the three experts, i.e., $\delta=\frac{7.8072+34.4985+89.8560}{5 \times 3+3 \times 20+3 \times 3 \times 20}=0.5183$; therefore, according to the data at the data input stage, the overall risk attitude of the selection committee formed by these three experts is optimistic.

Then, by utilizing Eq. (11), we can obtain

$$
\begin{aligned}
& x_{l}=\min \{0.1016,0.1507,0.0675\}=0.0675, \\
& x_{r}=\max \{0.4283,0.5308,0.3447\}=0.5308,
\end{aligned}
$$




$$
\begin{aligned}
U_{T}^{R}\left(\tilde{F}_{X}\right)= & (0.5183) \times\left(\frac{0.4283-0.0675}{0.5308-0.0675-0.2978+0.4283}\right)+ \\
& (1-0.5183) \times\left(1-\frac{0.5308-0.1016}{0.5308-0.0675+0.1772-0.1016}\right)=0.4130, \\
U_{T}^{R}\left(\tilde{F}_{Y}\right)= & 0.5567, \\
U_{T}^{R}\left(\tilde{F}_{Z}\right)= & 0.2994 .
\end{aligned}
$$

From the above results, the final ranking value of the three middle-manager candidates can be found. The results can be shown as $U_{T}^{R}\left(\tilde{F}_{Y}\right)>U_{T}^{R}\left(\tilde{F}_{X}\right)>U_{T}^{R}\left(\tilde{F}_{Z}\right)$. Therefore, based on the ranking rules in Section 2.3, the HR department of the international shipping company will suggest that candidate $Y$ is the best middle manager.

\section{Conclusions}

The international shipping logistics industry is an important logistics auxiliary for the international transportation industry. In order to provide better shipping logistics services, enterprises must recruit, cultivate, and retain outstanding talents continuously so as to form an efficient work team and achieve the organizational goal. Excellent manpower is also a key factor of a successful enterprise. In particular, middle managers play the role of transferring important information between the operational department and the decision-making department among the organizational managers. Therefore, selecting a middle manager with management competency and capability has a decisive impact on organizational development. Especially, HR departments often have to choose from many candidates during the process of employee evaluation and selection. In order to make a choice, it is necessary to set criteria for evaluation and comparison, so as to choose the most suitable manager from numerous candidates. In addition, a middle manager's management competency and capability involves numerous evaluation dimensions and evaluation criteria, and the research scope and level covered by it is extensive and complex. As a result, the main purpose of this article was to establish a fuzzy evaluation model so that international shipping service providers can make the most suitable choice under a fuzzy environment.

In this article, a five-step fuzzy MCDM model was proposed to improve the quality of decision-making for choosing the best middle manager. In the proposed evaluation model, combining the academic literature and the scholars' and experts' opinions, a hierarchy structure with five assessment aspects, 20 assessment criteria and three candidates was constructed. The fuzzy weights for all assessment aspects and assessment criteria were obtained using the concept of linguistic variables and the arithmetic mean, as well as the evaluation of the performance value (the appropriateness rating) in this study. The comprehensive evaluation values for all alternatives were then evaluated. Based on the ranking method of the maximizing and minimizing sets, the best middle manager will be finally determined.

We applied a simulation example to interpret the calculation process of this fuzzy MCDM model. In this numerical case, a hierarchy structure was developed. Then, a threemember-committee was formed to thoroughly evaluate the three potential candidates of middle managers in order to select the most qualified one. In addition, the overall risk attitude of the selection committee is optimistic, which is based upon the procedure of the data input stage. The risk attitude indicates that the committee with three experts is risk-lovers. Hence, based on the proposed fuzzy MCDM evaluation model, the candidate $Y$ is finally chosen as the best middle manager for the international shipping company. Moreover, in the end, the 
evaluation model and calculation process of this article were used to achieve the goal set by this paper.

The evaluation model developed in this article can be developed into a practical tool for business applications. In a fuzzy environment, companies can use this model to develop a decision support system to help them make decisions on related choices. Furthermore, the proposed fuzzy evaluation model can be applied in the similar decision-making problems [29, 30], such as partner selection of a strategic alliance in liner shipping carriers, best shipbuilding selection problem, best vessel selection, location choice of logistic centres, location selection of transshipment ports, and so on.

\section{REFERENCES}

[1] Notteboom, T. and Rodrigue, J.: Containerisation, box logistics and global supply chains: The integration of ports and liner shipping networks. Maritime Economics \& Logistics, 10(1-2), 152-174, 2008. https://doi.org/10.1057/palgrave.mel.9100196

[2] Liu, L., Wang, K. Y. and Yip, T. L.: Development of a container port system in Pearl River Delta: Path to multi-gateway ports. Journal of Transport Geography, 28, 30-38, 2013. https://doi.org/10.1016/j.jtrangeo.2012.10.002

[3] Gharehgozli, A. H., Roy, D. and Koster, R.: Sea container terminals: New technologies and OR models. Maritime Economics \& Logistics, 18(2), 103-140, 2016. https://doi.org/10.1057/mel.2015.3

[4] Prajogo, D., Oke, A. and Olhager, J.: Supply chain processes: Linking supply logistics integration, supply performance, lean processes and competitive performance. International Journal of Operations \& Production Management, 36(2), 220-238, 2016. https://doi.org/10.1108/IJOPM-03-2014$\underline{0129}$

[5] Rodrigue, J.: The geography of global supply chains: Evidence from third-party logistics. Journal of Supply Chain Management, 48(3), 15-23, 2012. https://doi.org/10.1111/j.1745-493X.2012.03268.X

[6] Jones, G. R. and George, J. M.: Essentials of Contemporary Management ( $6^{\text {th }}$ ed.). New York: McGrawHill, 2015.

[7] Kiessling, T. and Harvey, M.: Human resource management issues associated with the globalization of supply chain management and logistics. International Journal of Physical Distribution \& Logistics Management, 44(8/9), 2014. https://doi.org/10.1108/IJPDLM-05-2014-0115

[8] DuBrin, A. J.: Essential of Management ( $9^{\text {th }}$ ed.). Singapore: Thomson South-Western, 2011.

[9] Robbins, S. P., DeCenzo, D. A. and Coulter, M.: Fundamentals of Management: Essential Concepts and Applications ( $9^{\text {th }}$ ed.). Singapore: Pearson Education, 2014.

[10] Fang, C. H., Chang, S. T. and Chen, G. L.: Competency development among Taiwanese healthcare middle manager: A test of the AHP approach. African Journal of Business Management, 4(13), 2845$2855,2010$.

[11] Ding, J. F.: Using fuzzy MCDM to select partners of strategic alliances for liner shipping. Information Sciences, 173(1-3), 197-225, 2005. https://doi.org/10.1016/j.ins.2004.07.013

[12] Zadeh, L. A.: Fuzzy sets. Information and Control, 8(3), 338-353, 1965. https://doi.org/10.1016/S00199958(65)90241-X

[13] Ali, A. R.., Milan, N. and Dragan, Ć.: Applications of fuzzy decision making for personnel selection problem: A review. Journal of Engineering Management and Competitiveness, 4(2), 68-77, 2014. https://doi.org/10.5937/jemc1402068A

[14] Kusumawardani, R. P. and Agintiara, M.: Application of fuzzy AHP-TOPSIS method for decision making in human resource manager selection process. Procedia Computer Science, 72, 638-646, 2015. https://doi.org/10.1016/j.procs.2015.12.173

[15] Sang, X., Liu, X. and Qin, J.: An analytical solution to fuzzy TOPSIS and its application in personnel selection for knowledge-intensive enterprise. Applied Soft Computing, 30, 190-204, 2015. https://doi.org/10.1016/j.asoc.2015.01.002 
[16] Karabasevic, D., Zavadskas, E. K., Turskis, Z. and Stanujkic, D.: The framework for the selection of personnel based on the SWARA and ARAS methods under uncertainties. Informatica, 27(1), 49-65, 2016. https://doi.org/10.15388/Informatica.2016.76

[17] Dahooie, J. H.., Abadi, E. B. J., Vanaki, A. S. and Firoozfar, H. R.: Competency-based IT personnel selection using a hybrid SWARA and ARAS-G methodology. Human Factors and Ergonomics in Manufacturing \& Service Industries, 28(1), 5-16, 2018. https://doi.org/10.1002/hfm.20713

[18] Efe, B. and Kurt, M.: A systematic approach for an application of personnel selection in assembly line balancing problem. International Transactions in Operational Research, 25(3), 1001-1025, 2018. https://doi.org/10.1111/itor.12439

[19] Dubois D. and Prade, H.: Operations on fuzzy numbers. The International Journal of Systems Science, 9(6), 613-626, 1978. https://doi.org/10.1080/00207727808941724

[20] Zadeh, L. A.: The concept of a linguistic variable and its application to approximate reasoning, Part 1, 2 and 3. Information Sciences, 8(3), 199-249, 1975; 8(4), 301-357, 1975; 9(1), 143-80, 1976.

[21] Ghyym, S. H.: A semi-linguistic fuzzy approach to multi-actor decision-making: Application to aggregation of experts' judgments. Annals of Nuclear Energy, 26(12), 1097-1112, 1999. https://doi.org/10.1016/S0306-4549(98)00113-3

[22] Chen, S. H.: Ranking fuzzy numbers with maximizing and minimizing set. Fuzzy Sets and Systems, 17(2), 113-129, 1985. https://doi.org/10.1016/0165-0114(85)90050-8

[23] Kim, K. and Park, K. S.: Ranking fuzzy numbers with index of optimism. Fuzzy Sets and Systems, 35(2), 143-150, 1990. https://doi.org/10.1016/0165-0114(90)90189-D

[24] Chang, P. L. and Chen, Y. C.: A fuzzy multi-criteria decision making method for technology transfer strategy selection in biotechnology. Fuzzy Sets and Systems, 63(2), 131-139, 1994. https://doi.org/10.1016/0165-0114(94)90344-1

[25] Chen, P., Partington, D. and Wang, J. N.: Conceptual determinants of construction project management competence: A Chinese perspective. International Journal of Project Management, 26(6), 655-664, 2008. https://doi.org/10.1016/j.ijproman.2007.09.002

[26] Crawford, L. and Nahmias, A. H.: Competencies for managing change. International Journal of Project Management, 28(4), 405-412, 2010. https://doi.org/10.1016/j.ijproman.2010.01.015

[27] Fisher, E.: What practitioners consider to be the skills and behaviours of an effective people project manager. International Journal of Project Management, 29(8), 994-1002, 2011. https://doi.org/10.1016/j.ijproman.2010.09.002

[28] Kotzab, H., Teller, C., Bourlakis, M. and Wünsche, S.: Key competences of logistics and SCM professionals - The lifelong learning perspective. Supply Chain Management: An International Journal, 23(1), 50-64, 2018. https://doi.org/10.1108/SCM-02-2017-0079

[29] Aikhuele, D. O. and Turan, F. B.: An improved methodology for multi-criteria evaluations in the shipping industry. Brodogradnja, 67(3), 59-72, 2016. https://doi.org/10.21278/brod67304

[30] Tsai, J. Y., Ding, J. F., Liang, G. S. and Ye, K. D.: Use of a hybrid MCDM method to evaluate key solutions influencing service quality at a port logistics center in Taiwan. Brodogradnja, 69(1), 89-105, 2018. https://doi.org/10.21278/brod69106

Submitted: 22.06 .2018 . Accepted: 05.02.2019.

\section{Ji-Feng Ding}

Department of Aviation and Maritime Transportation Management

Chang Jung Christian UniversityTainan 71101, Taiwan

TEL: +886-6-2785123 ext. 2263 FAX: +886-6-2785056

Corresponding author: jfding@mail.cjcu.edu.tw

Jung-Fong Kuo

Ph.D. Program in Business and Operations Management

Chang Jung Christian University, Tainan 71101, Taiwan

Wen-Hui Tai

Department of Tourism Management, Chia Nan University of Pharmacy \& Science Tainan 71710, Taiwan 